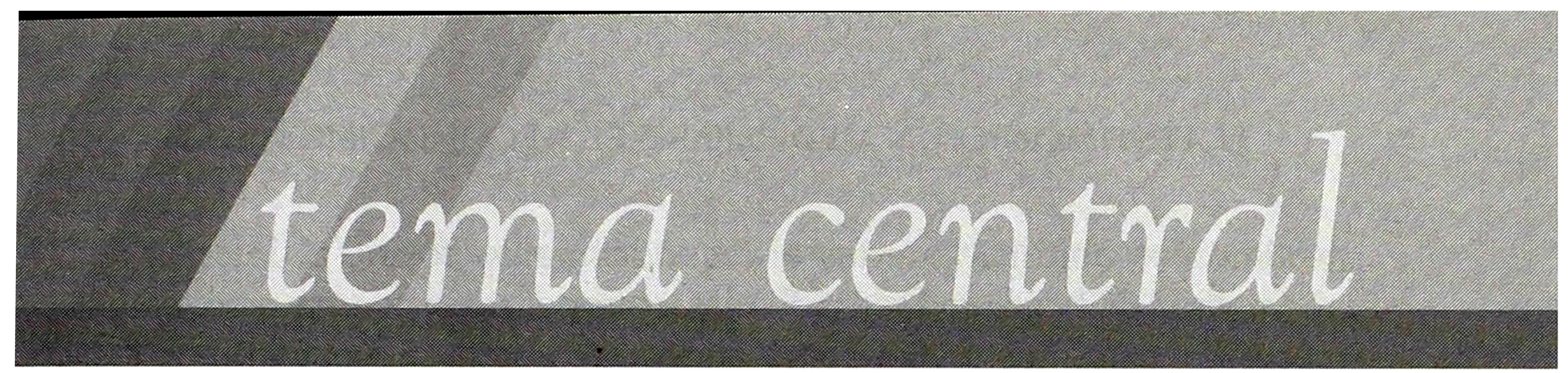

\title{
EL TESTIMONIO COMO MEDIO PARA EL RECONOCIMIENTO DE LOS DERECHOS HUMANOS
}

Lupe Jara ${ }^{1}$

Que no calle el cantor porque el silencio cobarde apaña la maldad que oprime, no saben los cantores de agachadas, no callarán jamás frente al crimen².

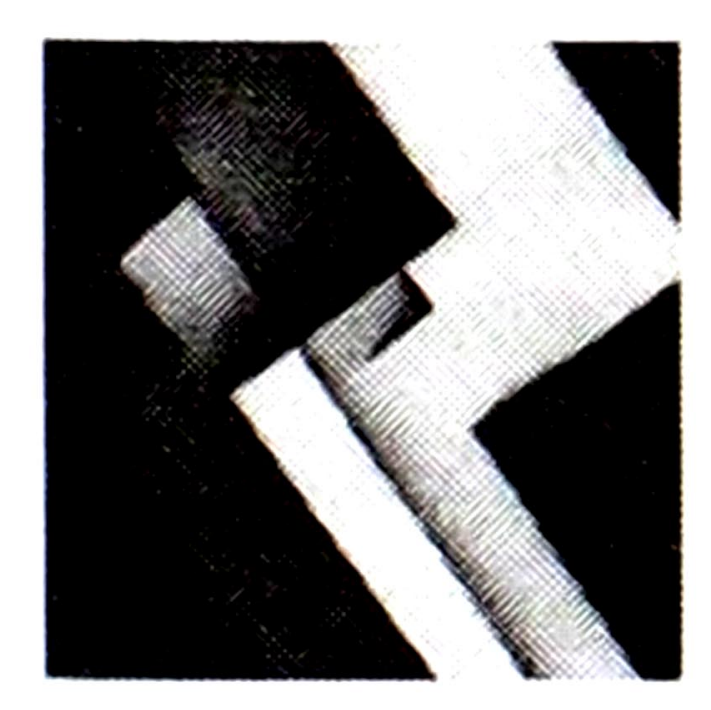

Aunque el dolor de las víctimas de la guerra interna que el Perú ha vivido es -como señaló Salomón Lerner, expresidente de la Comisión de la Verdad y la Reconciliación- «insondable y, en el fondo, irreparable» (Lerner, 2004: 129), acompañar, escuchar y recoger sus

${ }^{1}$ La autora agradece el apoyo brindado por la Dirección Académica de Investigación (DAI) de la Pontificia Universidad Católica del Perú para la realización de las entrevistas a personas afectadas por el conflicto armado interno, citadas en este texto. Asimismo, la autora agradece los comentarios y sugerencias del maestro Juan Carlos Guerrero Bravo.

${ }^{2}$ Horacio Guarany, Si se calla el cantor. 
testimonios abre las puertas al reconocimiento social, al intentar la reparación de sus dignidades robadas y atropelladas; no una, sino tantas veces. Estos daños tienen como agravante que la mayor parte de los afectados son - entre los pobres - los más pobres, aquellos que desde hace mucho tiempo se encuentran marginados y excluidos como ciudadanos frente al estado y a la sociedad. Al escaso goce de derechos, se sumaron inaceptables crímenes y atropellos $y$, también, una prolongada indiferencia del resto de la sociedad ante sus sufrimientos.

Durante muchos años, la población peruana prefirió voltear el rostro, no mirar de frente, no hacer caso de la tragedia que estaban viviendo sus hermanos más humildes. Esa condena al silencio, ese olvido por parte del Estado y de la sociedad, también es una forma de arrebatarnos nuestra dignidad (Lerner, 2002).

Lejos de proteger a sus ciudadanos más humildes, el propio estado vulneró sus derechos, en tanto que la sociedad no sólo no confortó ni acogió a las víctimas, sino que, por el contrario, los ignoró o los trató con desprecio. «Nos trataban de piojosos, serranos, indios de mierda». De ahí que la Comisión de la Verdad y Reconciliación (CVR) considere que ningún trance en la historia de nuestro país esté "marcado tan rotundamente con el sello de la vergüenza y el deshonor» como la que ella estuvo obligada a contar.

No obstante, es necesario recuperar la memoria para comenzar a edificar nuestro futuro, pues al conocer lo que pasó, se puede saber "por qué sucedió, qué se destruyó y cómo emprender procesos reales de reconstrucción y reparación» (Boraine, 2000: 1). Un medio que permite dejar al descubier to la historia del país y sus dolorosas divisiones para su revisión pública son los testimonios de los propios afectados. Testimonios que cuando son recogidos por instancias oficiales - como las comisiones de la verdad - pasan de ser rechazados, manipulados o respondidos con violencia a ser escuchados, atendidos y acompañados. Ello constituye un canal para relacionar el dolor personal de las víctimas con el dolor de la colectividad $y$, a la vez, un reconocimiento de que las atrocidades cometidas fueron reales e injustas (Hayner, 2003).

En octubre de 1984 solía despertar con el miedo incrustado en el pecho como si fuera un cuchillo helado. 


\section{LUPE JARA}

Tenía la edad en que ustedes piensan que serán grandes o tan sólo en salir a jugar con otros niños.

En mi vida tal etapa fue suprimida. Desde que se instaló el terror, por las mañanas sólo tenía una urgencia...

Correr al cuarto de papá y comprobar que estuviera vivo... (Machuca, en Portugal 2005: 57)

\section{EL TESTIMONIO COMO MEDIO PARA EL RECONOCIMIENTO}

Un mecanismo hallado por la CVR para «hacer que todo el país escuche y comience a sentir como propia esa tragedia" (Lerner, 2002) fue el testimonio ante las audiencias públicas. «He visto las audiencias, me he dado cuenta que 'esa' gente sufre»'. Así como en esta instancia formada por el estado, el testimonio de las víctimas también se ha escuchado o leído en diferentes espacios y medios que le han dado la palabra a quienes durante años guardaron silencio sobre atropellos y crímenes que laceran la humanidad.

Estas acciones logran restablecer públicamente la dignidad humana y cívica de los afectados, al otorgarle a la verdad un sentido de reconocimiento social y al restituir tanto el respeto moral igualitario entre los ciudadanos, como la conciencia de derechos (Du Toit, 2000). Para ello, se espera que la sociedad sea solidaria y reconozca en cada víctima a un semejante y un ciudadano «con sus voces y sus esperanzas».

El testimonio público permite que ese costo estadístico de la violencia ${ }^{4}$ tenga rostro y pueda ser visto como una persona con derechos, no como un objeto de conmiseración o sospecha.

Se trata de casos radicalmente humanos y cada uno de ellos debe ser entendido como la realidad absoluta que es: una vida humana perdida, una familia destrozada, una comunidad destruida (Lerner, 2004: 124).

${ }^{3}$ Entrevista a hombre adulto, docente universitario, residente en Lima, nivel socioeconómico medio-medio. El comentario que pretende ser empático, no deja de mostrar la distancia con la víctima. 
[...] los militares entraron rompiendo las puertas de mi casa y a mi madre la asesinaron en la cocina, y a mi anciano padre lo acribillaron en su cama, robando sus ahorros y recuerdos; jalando como si fueran animales, arrastrándoles y llenos de sangre, los trajeron a la plaza; para terminar descuartizándoles y procediendo a quemarlos heridos y asesinados; después de quemar, lo que no han podido quemarlos, lo han llevado para hacer desaparecer por los cerros, huaycos, donde los animales lo han terminado de comer. Luego fueron a la casa de mis padres e hicieron volar en pedazos para no dejar huellas de lo sucedido, lo mismo hicieron con mi casa ${ }^{5}$.

Los testimonios exponen cómo el abuso, la tortura, la vejación y la muerte irracional se enseñorearon un día entre nosotros. Sin embargo, abrimos un nuevo camino al acompañar a los testimoniantes cuando aprendemos que la muerte no es irremediable, si podemos recordar y honrar la memoria de quien ha partido, si podemos animar al sobreviviente a salir de su abismo silencioso, si puede él rescatarnos de la indiferencia. Inauguramos un encuentro, reconociendo ambos nuestra historia compartida.

¿Nuestra escucha respetuosa, pero sorprendida, indignada, quebrantada con cada palabra de estos semejantes que emergieron del olvido para mostrarnos las huellas de su dolor y de su valor, puede en algo ayudar a sanarlos, a reconstruir la esperanza, a reconciliarnos?

Cuando fui a mi puesto [en el mercado], la gente me recibió llorando, me habían visto por la televisión dando mi testimonio [en las Audiencias Públicas], 'ipor qué no nos contaste?, mira todo lo que te ha pasado', lloraban tanto que tuve que consolarlos ${ }^{6}$.

${ }^{4}$ Entrevista a hombre adulto con educación superior, residente en Lima, nivel socioeconómico medio-alto.

${ }^{5}$ Testimonio de ARB, mujer adulta ayacuchana. Se desplazó a Lima por la violencia. Es miembro de una agrupación de familiares afectados por el conflicto armado.

${ }^{6}$ Entrevista a MA. La primera vez que la señora MA llegó a la CVR-Región Centro lucía el luto en su rostro y en su ropa. Llegó muchas veces a la Comisión para contar nuevamente "su caso", cada vez que lo hacía, vaciaba sus lágrimas inagotablemente y siempre volvía, con la misma tristeza y el mismo dolor. Con dudas se eligió su testimonio para ser presentado en las Audiencias Públicas, pues se temía que la experiencia fuese muy dura para ella. Ese día sus lágrimas se quedaron en el escenario. Cuando bajó, algo en ella había cambiado. La siguiente vez que la vimos vestía ropa de colores, se había maquillado, usaba aretes y en su rostro, por primera vez, encontramos una sonrisa. 


\section{LUPE JARA}

Durante las audiencias públicas - por ejemplo-, el estar ahí con ellos, escuchando "su verdad", sin interrogarlos, sin confrontarlos con sus perpetradores, sentados en la misma mesa horizontal que los comisionados, con psicólogos que los acompañaron antes, durante y después del testimonio, con su familia o gente de su comunidad entre el público, con algunas autoridades, invitados extranjeros y medios de comunicación presentes; todo ello parece haber creado las condiciones emocionales para que los testimoniantes se sintieran en un ambiente seguro, cercano, confiado, cuidado y donde eran valorados.

Señores públicos, señores periodistas, señores visitantes, señores Comisión de Verdad, muchísimas gracias. Me ha invitado acá, pero istoy alegre, está quedando por primera vez, nosotros vamos estar acá con ostedes, todo junto, pero yo voy a hablar con mi quechua?.

A pesar de la tragedia vertida en los testimonios, un ambiente de acogida favorece que aún se hable de esperanza, del derecho a una vida distinta.

Hasta este momento, yo no estoy tranquila, yo no soy feliz, no soy feliz, todas las cosas para mí ha sido un sacrificio desde el momento en que mi madre desapareció. Todo... nada fue fácil para mí, nada, nada fue fácil. Tuve que hacer miles de cosas para sobresalir, mi hermano igual, y nosotros necesitamos, tenemos derechos a ser feliz. Hasta ahora yo pienso y necesito ser feliz, tal vez sólo por esa fuerza estoy aquí. Yo quiero ser feliz, señores ${ }^{8}$.

Exponer su verdad - de acuerdo a Boraine (2000) - le asesta un «golpe certero a la negación" y alienta profundamente a las víctimas y sobrevivientes a «dejar el pasado atrás y retomar nuevamente sus vidas sin la sombra constante de la incertidumbre y la pérdida de dignidad y reconocimiento" (pág. 27). Cuando se puede, sin desaparecer, cambiar el estatuto de la herida, empieza el lento camino de la recuperación emocional de las víctimas, debido a que se permite que el duelo por el pasado tenga lugar.

7 Testimonio de Angélica Mendoza, audiencias públicas de la CVR (Huamanga, 8 de abril del 2002). En adelante, los énfasis en cursiva son de la autora.

8 Testimonio de Liz Rojas (23 años, ayacuchana), Audiencias Públicas de la CVR (Huamanga, 8 de abril del 2002). 
No hay olvido ni se niega la tragedia, pero la herida va dejando el presente. No sólo se rompe el silencio, se da inicio a un proceso en el que el duelo es el inicio y la reconciliación, la meta. En este proceso estamos todos, pues si en la violación estuvieron presentes perpetrador, víctima y sociedad, en el restablecimiento de la verdad y justicia también todos ellos deben estar involucrados.

La herida está herida, nada podrá sanarla, quizás si se atiende nuestros pedidos pueda haber un consuelo?.

Empero, estos actos públicos generan inevitablemente sentimientos de ansiedad y preocupación en los testimoniantes, tanto por tener que compartir experiencias donde su dignidad fue vejada de mil maneras, como por el temor a que la emoción ante los hechos relatados dificulte su desempeño y no logren hacer un relato coherente y preciso: «siempre con el temor: "voy a hablar, pero de repente si lo hago mal, voy a tener cargo de conciencia' "10. Existe, además, la conciencia de ser representante de otras víctimas que han vivido situaciones semejantes.

Tenía que pensar en ese momento que es muy importante para que el mundo entero se entere qué es lo que paso con nuestros hermanos peruanos, cuál fue la verdad de la violencia política que azotaron a mucha gente, a nuestros hermanos peruanos, $y$ más que nada a la gente humilde. Entonces, pienso, por más triste, por más doloroso que haiga sido mi testimonio, entre mi pienso que es una labor que debo hacer, sólo de esa manera creo que podía yo conseguir o encontrar más solidarios en el camino y de repente encontrar más voces para que se pueda unir a nuestra voz de esa justicia, de esa verdad ${ }^{11}$.

9 Entrevista a $\mathrm{CH}$, mujer ayacuchana, cuyo esposo fue desaparecido. Se desplazó a Lima por la violencia. Es miembro de una agrupación de familiares afectados por el conflicto armado.

${ }^{10}$ Entrevista a CA, hermana de un estudiante desaparecido y ejecutado, residente en Lima.

$"$ Entrevista a $\mathrm{CH}$, mujer ayacuchana, cuyo esposo fue desaparecido. Se desplazó a Lima por la violencia. Es miembro de una agrupación de familiares afectados por el conflicto armado. 
Entonces, les preocupa presentar toda la información necesaria, temiendo que sin estos datos su historia sea dejada de lado, como les ha pasado antes:

[...] soy bastante autocrítica, porque parece que [antes] no tenía tanta claridad como la tengo ahora, la misma inexperiencia, los nervios, no lo sé, aprendimos en la práctica a desenvolvernos frente a todas las circunstancias que nos tocó vivir ${ }^{12}$.

Luego del testimonio, la aprobación y solidaridad de la gente ayuda a bajar esta ansiedad.

El chico [del público] de alguna forma mostró su solidaridad, 'ustedes han hecho un bien, una contribución al país'. El mismo reconocimiento en la calle, o de alguna forma en las mismas universidades, el mismo respeto que tienen, son varias $\operatorname{cosas}^{13}$.

Con este respaldo, se refuerza en ellos el sentimiento de haber accedido a algún tipo de reivindicación: ellos, sus familias o su comunidad.

Ahora, si bien los testimonios logran convocar la solidaridad y el apoyo concreto de un sector de la sociedad, no hay que olvidar que son momentos donde los afectados vuelven a exponerse al dolor de sus heridas. Aun así, se brinda el testimonio como una manera de rehumanizar "el caso", bajo el convencimiento de que, de esta manera, rinden homenaje a sus víctimas y a ellos mismos, como familiares o afectados.

Pese a que entendemos y sabemos y lo vivimos cada vez que nos toca hablar del tema es bien difícil y bastante doloroso para nosotros y siempre terminamos llorando - pese a que no queremos hacerlo, y siempre nos desgasta emocionalmente; si le damos importancia $e$ intentamos hacerlo es porque es la única forma de cómo tu puedes trasmitir esa parte de esa historia que se habla a veces como números o se habla como hechos tan aislados, pero que no [lo es]; realmente uno, a veces no lo dimensiona en el lado humano, y que además es

12 Entrevista a GO, hermana de un estudiante desaparecido y ejecutado, residente en Lima.

${ }^{13}$ Entrevista a CA, hermana de un estudiante desaparecido y ejecutado, residente en Lima. 


\section{EL TESTIMONIO, UN MEDIO PARA EL RECONOCIMIENTO...}

una forma de comprometer a que los jóvenes o los otros sectores quieran hacer algo en torno al tema ${ }^{14}$.

En medio del dolor, los testimoniantes tratan de buscar «signos» que los animen y los nutran de esperanza.

En el momento en que me presentan a mí, fue el sacerdote [quien lo presentó en las audiencias públicas]. Eso me gustó. 'Señores de la audiencia', me presentó él, y como que eso me hace tener esperanza, de lo que dijo antes y después, y que vaya a cumplir porque es un hombre de fe y eso es la confianza que yo tengo ${ }^{15}$.

Asimismo, cuando en los actos donde se brindan los testimonios participan autoridades y éstas se conmocionan con sus historias, el sentido de reconocimiento parece más cercano. Les sorprende que todos compartan sus sentimientos de duelo largamente postergados.

iTodos en duelo! Porque ese día se recordaron de la pérdida de sus familiares, cómo ellos han pasado, han vivido, cada cual ha lanzado, y con eso estábamos llenados de angustia. Todo el mundo ahí venían con lágrimas, porque se recordaron la muerte de sus hijos, de sus esposos, de sus paisanos, y cómo han sufrido, y no solamente yo he sido afectado por ambas partes, sino casi la mayoría. Casi masivamente han derramado sus lágrimas, porque cada cual que lanzaban, lanzaban una historia dolorosa ${ }^{16}$.

En el caso particular de las audiencias públicas, el testimonio se vivió con un sentido de duelo colectivo, pues todo el acto estuvo investido simbólicamente como el de un auténtico ritual, enfocado en el reconocimiento. Dado que la tragedia había significado el aislamiento social y el sentimiento de indefensión en los afectados, el hecho de vivir su dolor acompañados los dotó de certeza, seguridad, pertenencia a una comunidad. En esa comunidad, escucharon y conocieron a otras

${ }^{14}$ Entrevista a GO, hermana de un estudiante desaparecido y ejecutado, residente en Lima.

${ }^{15}$ Testimonio de hombre adulto (40 años), con discapacidades provocadas por atentado, residente en Lima. En CVR, 2006.

${ }^{16}$ Testimonio de hombre adulto (41 años), familiar de persona desaparecida, residente en Ayacucho. En CVR, 2006. 


\section{LUPE JARA}

personas con experiencias semejantes, despertando su solidaridad y el sentimiento de no estar solos:

Lo que sí sentí es la necesidad de unirnos, de juntarnos todos, porque si nos ha pasado lo mismo, ¿por qué no podemos estar juntos? Eso es lo que sentí, ¿no? Además, la necesidad y, en esos momentos, la solidaridad aflora. Los sentimientos son lo mismo, los casos son lo mismo, y eso aflora: a querer reunirnos y estar juntos, ¿no? Porque soy conciente de que no estoy solo, sino un conjunto de personas, miles de personas, y los que hemos testimoniado es apenas una parte ${ }^{17}$.

Por todo ello, existe una gran insatisfacción con la escasa cobertura que los medios de comunicación han prestado y siguen prestando al tema de derechos humanos. Este desinterés es una muestra más de la escasa solidaridad que despiertan los pobres y excluidos del país, y así lo entienden ellos. En tal sentido - a diferencia de la comisión sudafricana-, la CVR peruana no generó un impacto en la «psique popular» (Van Zyl, 2002) y tuvo dificultades para abrir un espacio en la conciencia ciudadana donde reflexionar nuestros grandes y graves problemas como nación y la necesidad de incluir a todos como parte de ese espacio.

Si bien es cierto ahora se viven otras épocas, donde la solidaridad podría ser mucho más evidente, es mucho más difícil, ¿por qué? Porque ya no hay el enemigo común que era la dictadura de Fujimori, ahora vivimos en democracia, y en realidad cada uno de los sectores, tanto estudiantiles, como sociales, están en sus propias exigencias... Y no somos capaces de juntarnos en torno a temas más concretos como son la lucha contra la impunidad, la búsqueda de justicia... En realidad, no hay un compromiso de otros sectores sociales que quieran hacer frente a ese hecho y de alguna manera seguimos siendo los familiares como las voces aisladas que seguimos denunciando que pasan los gobiernos, pero en realidad la esencia del Estado peruano sigue siendo encubrir a los criminales ${ }^{18}$.

${ }^{17}$ Testimonio de hombre adulto (59 años), familiar de persona ejecutada, residente en Lima. En CVR, 2006.

${ }^{18}$ Entrevista a GO, hermana de un estudiante desaparecido y ejecutado, residente en Lima. 
Sin embargo, más allá de si el testimonio es público o no, lo que parece central para los afectados es simplemente el acto de hablar y sentirse escuchados empáticamente. De ahí la existencia de los cerca de $17 \mathrm{mil}$ testimonios recogidos por la CVR, dados con gratuidad y sin obligación formal de por medio. Muchos, luego de dar su testimonio a la CVR la mayor parte de ellos lo hacía por primera vez-, expresaron un sentimiento de alivio, sencillamente por la oportunidad de contar sus historias -más aún, ante una instancia del estado-. Al hacerse escuchar, sintieron que reconquistaban su sentido de dignidad.

Así, ser escuchados por otro se transforma en una experiencia terapéutica que va reparando la psiquis. Esta es una experiencia compartida con las diferentes comisiones de la verdad en el mundo:

Siento que lo que me ha hecho sentir enfermo todo este tiempo es no haber podido contar mi historia. Pero ahora que he venido aquí y he contado mi historia, siento como si hubiera recuperado mi vista ${ }^{19}$.

Otro testimoniante expresó cómo este hecho afectó su vida profundamente, permitiéndole experimentar una mayor libertad:

Fui liberado de una prisión en la que he estado durante 18 años. Es como si mi familia hubiera sido igualmente liberada... El silencio se está terminando y estamos despertando de una larga y terrible pesadilla ${ }^{20}$.

Algunos encuentran —en estos espacios - la oportunidad de reivindicar la honra y el buen nombre de sus familiares, al haber afirmado su inocencia. Se cree, asimismo, que ante tantos testimonios, la sociedad no podrá negar lo ocurrido y se demostrará las prácticas violatorias de los derechos humanos. De otro lado, también aparece el deseo de justicia, esperando que se dicten sanciones contra los perpetradores y que el estado les brinde una reparación por los daños sufridos - muchos

${ }^{19}$ Lucas Sikwepere, testimoniante ante la CVR sudafricana. Citado en Boraine, 2000: 10.

${ }^{20}$ Tim Ledgerwood, testimoniante ante la CVR sudafricana. Citado en Boraine, 2000: 10. 


\section{LUPE JARA}

esperan que sus testimonios sirvan para que las autoridades tomen conciencia de sus reclamos-.

De esta forma, la experiencia de brindar su testimonio a la sociedad suele ser evaluada con esperanzas, con la confianza de haber ayudado a evitar que se repita la tragedia, en la medida que la sociedad toma conciencia del valor de los derechos humanos que asisten a cada ciudadano.

Ahora han entendido que sí hay un derecho que luchar, hay un derecho que pelear, ahora nos da esa razón la gente que nos miraba con diferente pensamiento o con esa ignorancia de sus derechos. Creo que también cabe señalar que a mucha gente hemos educado, hemos enseñado a conocer sus derechos, que no deberían callarse cuando le hacen la injusticia con su persona, con su familia. Creo que también ha sido un logro para nosotros, nos sentimos orgullosas porque de una $u$ otra manera, humildes hemos llegado a hacer entender a mucha gente... ${ }^{21}$

\section{DESAFÍOS: DERECHO HUMANOS PARA TODOS}

Aunque los espacios o medios donde brindar testimonio proporcionen un lugar para la redignificación de los afectados, éstos siguen siendo pobres y marginados. Con el testimonio pueden vivir momentos de reconocimiento, pero es claro que si sus demandas no son atendidas, los sentimientos de alivio experimentados pueden trocarse en frustración, rabia y el sentimiento de haber sido nuevamente "engañados». Puesto que la búsqueda de la justicia no declina con el transcurrir del tiempo (Teitel, 2003) y la verdad recogida por la CVR es un complemento y no una alternativa a la justicia retributiva, la lucha por el reconocimiento sigue buscando a los responsables de los crímenes y hacer posible una reparación para las víctimas (Nash, 2004).

Al respecto, aunque razones éticas, políticas y jurídicas sustentan la búsqueda de verdad, justicia y reparación, su viabilidad depende de las condiciones y el contexto del país, lo que plantea dilemas éticos entre las

${ }^{21}$ Entrevista a $\mathrm{CH}$, mujer ayacuchana, cuyo esposo fue desaparecido. Se desplazó a Lima por la violencia. Es miembro de una agrupación de familiares afectados por el conflicto armado. 
exigencias morales de estos objetivos y lo que es posible realizar. En el Perú, antes de encontrar los mecanismos para hacerlos efectivos, se requiere lograr consensos e interés en torno a ellos, a fin de que - por ejemplo- la verdad revelada por la CVR tenga sentido para la sociedad.

Hasta ahora, la sociedad sigue siendo extraña a los reclamos de los afectados, por lo que el impacto de las exigencias de éstos en la agenda pública sigue siendo débil. ¿Cómo emprender la lucha por la reparación integral de las víctimas con una sociedad de espaldas a ella? El panorama no es alentador, pero la tarea debe abordarse, dando respuesta a esa vieja y asentada desigualdad que habita entre nosotros y a esa convivencia social quebrada por la violencia y la corrupción. Atender estos pendientes es indispensable para darle viabilidad a un estado democrático y para abrir una brecha en la historia que nos permita refundar una nación para todas y todos. En esta aspiración, el modelo ético de los derechos humanos brinda el marco en el cual es posible generar nuevas relaciones basadas en la dignidad, libertad e igualdad de las personas (Squella, 2000).

La reconciliación - al buscar la reconstitución de un vínculo que se ha roto- implica un proceso extraordinariamente difícil - $e$, incluso, doloroso- que tiene que ser alcanzado por toda la comunidad. Este proceso tiene como pilar la verdad, pero también la justicia y la paz. En esa justicia está implícita el reconocimiento de responsabilidad y el resarcimiento de las víctimas. Comprendemos por paz a la justicia social en la que la atención al alivio de la pobreza debe ser parte de la agenda. Una justicia que permita no sólo la sobrevivencia, sino la posibilidad de crear oportunidades para el desarrollo de proyectos de vida con futuro para las víctimas.

Como señala Theidon (2004), «no podemos reparar individuos sin reparar el entorno social en el cual viven» (pág. 42). La sanación del pasado implica el mejoramiento de la calidad de vida de todos los ciudadanos, así como la creación de una sociedad sin discriminación racial o de género (Mbeki, citado en Boraine, 2000: 7).

Al respecto,

[...] el reconocimiento y la protección de los derechos socioeconómicos son cruciales para el desarrollo y sustento de una cultura de respeto por los derechos humanos (Boraine, 2000: 13). 


\section{LUPE JARA}

Sin embargo, en la recuperación del orden moral y la justicia económica juegan en contra la debilidad de las organizaciones de las víctimas, que se movilizan por reclamos muy puntuales $y$-luego del informe final de la CVR - se han centrado en la expectativa del cumplimiento del Programa Integral de Reparaciones (PIR), sin articular sus demandas con otros sectores de la sociedad, en una misma perspectiva de lucha por derechos.

De esta manera, sus expectativas quedan atomizadas y pueden ser motivo de frustración, dado que no se consideran las posibilidades reales de alcanzar algún beneficio y los plazos en los que éstos puedan darse. Ello es especialmente cierto para quienes cuentan con menor información o menor experiencia organizativa; esto es, los afectados provenientes de los sectores con mayor necesidad económica (CVR, 2006).

Otro aspecto importante que requiere reflexión y atención son las jerarquías y exclusiones basadas en las diferencias culturales y étnicas: "la pobreza fue terrible, pero el maltrato fue peor». Casi todos los testimonios reflejan el trato "como animales» al que fueron sometidas las víctimas. La mención reiterada de este aspecto en los testimonios denota una exigencia de reconocimiento de humanidad, más allá de la ciudadanía. El «estado tiene que darse cuenta que estamos vivos». En efecto, el pueblo campesino, el pueblo pobre no pueden seguir siendo el estrato invisible de nuestra sociedad, no puede seguir siendo postergado.

Los peruanos solíamos decir, en nuestras peores previsiones, que la violencia había dejado 35 mil vidas perdidas. ¿Qué cabe decir de nuestra comunidad política, ahora que sabemos que faltaban 35 mil más de nuestros hermanos sin que nadie los echara de menos? (Lerner, 2003).

Es claro que la reforma del estado pasa por la construcción de una nación inclusiva que comprenda a esa mayoría que se encuentra actualmente al margen de un desarrollo mínimo, tanto legal como material (O'Donnell, 2004), lo cual redunda en una negación de ciudadanía que se evidencia en la inexistencia y la falta de implementación de derechos, y en múltiples prácticas de discriminación. Para alcanzar una convivencia respetuosa, los estados están obligados 
no sólo a la protección de los derechos humanos, sino también a su promoción para que «todos puedan gozar de ellos» (Medina, 2003).

El estado peruano viene fallando como realizador del bien común, a pesar de haber firmado convenios y compromisos internacionales al respecto. Además, debe enfrentar una corrupción institucionalizada, escasa participación ciudadana - $e$, incluso, un débil concepto de ciudadanía-, grupos de poder que fomentan "desigualdades sistemáticas, haciendo posibles ciertas vidas blancas al costo de muchas vidas indias» (Weismantel, 1997 en Theidon, 2004: 55).

Frente a ello, debemos ir construyendo pequeñas islas que nos brinden certezas en el "océano de la incertidumbre» (Boraine, 2000: 18), y comprometernos a desarrollar una fuerte cultura de derechos, si es que aspiramos a que la reconciliación sea una realidad para todos. 


\section{bibliografia}

BORAINE, A.

2000 «Reconciliación, ¿a qué costo? Los logros de la Comisión de la Verdad y Reconciliación», artículo traducido al castellano por el Centro de Derechos Humanos, Facultad de Derecho, Universidad de Chile, 28 pp. ( "What price reconciliation? The achievement of the TRC, en: A Country Unmasked, Oxford University Press, Southern Africa, pp. 340-378).

COMISIÓN DE ENTREGA DE LA COMISIÓN DE LA VERDAD Y RECONCILIACIÓN

2004 Hatun Willakuy. Versión abreviada del Informe Final de la Comisión de la Verdad y Reconciliación, Comisión de la Verdad y Reconciliación, Lima.

\section{COMISIÓN DE LA VERDAD Y RECONCILIACIÓN}

2006 El impacto de las audiencias públicas en los participantes (extraído, el 20 de octubre de 2006, de: http:// www.cverdad.org.pe).

2006 Informe final (extraído, el 20 de octubre de 2006, de: http:// www.cverdad.org.pe).

DU TOIT, A.

2000 «Los fundamentos morales de las comisiones de verdad. La verdad como reconocimiento y la justicia como aceptación: principios de la justicia transicional en la práctica de la Comisión de Verdad y Reconciliación (CVR) sudafricana», artículo traducido al castellano por el Centro de Derechos Humanos, Facultad de Derecho, Universidad de Chile («The Moral Foundations of Truth Commissions. Truth as Acknowledgement 
and Justice as Recognition: Principles of Transitional Justice in the Practice of the South African TRC», en: Rotberg, R. Truth $v$. Justice, Princeton University Press)

HAYNER, P.

2003 «Enfrentando crímenes pasados y la relevancia de comisiones de verdad", en: Ensayos sobre justicia transicional, Centro Internacional para la Justicia Transicional, pp. 117-138.

LERNER, S.

2002 Discurso inaugural de las audiencias públicas (http:// www.cverdad.org.pe).

2003 Discurso de presentación del informe final de la Comisión de la Verdad y Reconciliación, 28 de agosto de 2003 (http:// www.cverdad.org.pe).

2004 La rebelión de la memoria. Selección de discursos, 2001-2003, IDEHPUCP/ Coordinadora Nacional de Derechos Humanos/ CEP, Lima.

MEDINA, C.

2003 Derecho internacional de los derechos humanos, Centro de Derechos Humanos, Facultad de Derecho de la Universidad de Chile.

NASH. C.

2004 Las reparaciones en la jurisprudencia de la Corte Interamericana de Derechos Humanos, Centro de Derechos Humanos, Facultad de Derecho de la Universidad de Chile.

O'DONNELL, G.

2004 «Acerca del estado en América Latina contemporánea: diez tesis para discusión", en: PNUD, La democracia en América Latina. Hacia una democracia de ciudadanas y ciudadanos. Estudios para el debate, 2004, pp. 149-191.

PORTUGAL, T.

2005 ¿Dónde están nuestros héroes y heroínas? El sentido de la vida heroica en el Perú, SUR, Lima. 


\section{LUPE JARA}

SQUELLA, A.

2000 "Los derechos fundamentales de la persona humana", Introducción al Derecho, Editorial Jurídica de Chile, pp. 157202.

TEITEL, R.

2003 "Genealogía de la justicia transicional», artículo traducido al castellano por el Centro de Derechos Humanos, Facultad de Derecho, Universidad de Chile ("Transitional Justice Genealogy", Harvard Human Rights Journal, vol. 16, Cambridge, MA, pp. 69-94).

\section{THEIDON}

2004 Entre prójimos. El conflicto armado interno y la política de la reconciliación en el Perú, IEP, Lima.

\section{VAN ZYL, P.}

2002 «Tarea inconclusa: la contribución de la Comisión de la Verdad y Reconciliación a la justicia en la Sudáfrica post apartheid», en Comisión de Derechos Humanos del Distrito Federal, Memoria del Seminario Internacional: Tortura, reparación y prevención. Comisiones de la verdad, México, 2003, pp. 181-206. 